\title{
Amor: múltiplos significados por diferentes atores sociais
}

\author{
Love: multiple meanings by different social actors \\ Amor: múltiples significados por diferentes actores sociales
}

\author{
Millena de Assis Andrade \\ ORCID: https://orcid.org/0000-0001-8028-7053 \\ Terapeuta Ocupacional, Brasil \\ E-mail: millenaandrade1@outlook.com \\ Luana Foroni Andrade \\ ORCID: https://orcid.org/0000-0003-2765-1535 \\ Universidade Federal de Sergipe, Brasil \\ E-mail: luanaforoni@gmail.com \\ Priscila Yukari Sewo Sampaio \\ ORCID: https://orcid.org/0000-0001-9571-613X \\ Universidade Federal de Sergipe, Brasil \\ E-mail: pryukari@academico.ufs.br \\ Maria Suely Silva Melo \\ ORCID: https://orcid.org/0000-0003-1899-3963 \\ Universidade Federal de São Carlos, Brasil \\ E-mail: maria.suelysilva.melo@gmail.com \\ Raphaela Schiassi Hernandes \\ ORCID: https://orcid.org/0000-0002-9290-1003 \\ Universidade Federal de Sergipe, Brasil \\ E-mail: rapha_to@hotmail.com
}

\begin{abstract}
Resumo
É possível perceber que com as transformações da sociedade atual, como o individualismo exacerbado, o culto ao corpo e a imagem, as relações sociais são construídas e desconstruídas com facilidades, pois os vínculos são frágeis e superficiais. Entretanto, apesar de todas as modificações, o amor sobrevive intensamente nos entremeios dos lugares das responsabilidades sociais. Desta forma, a pesquisa caracteriza-se como um estudo qualitativo, quantitativo e descritivo, com o objetivo geral de compreender o significado de amor, para diferentes atores sociais, em contextos diversos. Os objetivos específicos são: identificar líderes de esferas sociais, comunitárias, empresariais e religiosas no território de pesquisa como atores sociais; identificar características mais comumente atribuídas e/ou associadas à palavra amor por diferentes atores sociais e comparar as possíveis semelhanças e diferenças dos significados de amor para os diferentes atores sociais. Os resultados da pesquisa mostraram que apesar dos significados de amor estarem relacionados com a experiência de vida de cada participante, todos concordaram que é um sentimento positivo, e para a maioria, o sentimento mais importante da vida, assim, pode-se pensar que pelo amor ser uma experiência única que permite que a subjetividade se faça presente, sua presença favoreceria uma descentralização da atenção voltada ao externo, e da exacerbação dos afetos e sentimentos negativos, construindo relações sociais mais sólidas e significativas, por isso, as discussões sobre o "amor" são de grande importância para o desenvolvimento de subsídios para propostas de incentivo em valores morais.
\end{abstract}

Palavras-chave: Amor; Sentimentos; Emoções; Relações sociais.

\begin{abstract}
It is possible to see that with the transformations of current society, such as exacerbated individualism, the cult of the body and the image, social relations are easily constructed and deconstructed, as the bonds are fragile and superficial. However, despite all the changes, love survives intensely between the places of social responsibilities. Thus, the research stands out as a qualitative, quantitative and descriptive study, with the general objective of understanding the meaning of love, for different social actors, in different contexts. The specific objectives are: to identify social, community, business and religious leaders in the research territory as social actors; identify the characteristics most commonly attributed and/or associated with the word love by different social actors and compare the similarities and differences in the meanings of love for different social actors. The results of the research induced that despite the meanings of love being related to the life experience of each participant, all agreed that it is a positive feeling, and for most, the most important feeling in life, so one can think that by love being a unique experience that allows subjectivity to be present, its presence would favor a decentralization of attention focused on the external, and the exacerbation of corporate affections and feelings, building more solid and specific social relationships, therefore, the obligations on " love" are of great importance for the development of subsidies for proposals to encourage moral values.
\end{abstract}

Keywords: Love; Feelings; Emotions; Social relationships. 


\begin{abstract}
Resumen
Es posible percibir que con las transformaciones de la sociedad actual, como el individualismo exacerbado, el culto al cuerpo ya la imagen, las relaciones sociales se construyen y deconstruyen con facilidad, por lo que los vínculos son frágiles y superficiales. Sin embargo, a pesar de todas las modificaciones, el amor sobrevive intensamente en medio de los lugares de las responsabilidades sociales. De esta forma, la investigación se caracteriza por ser un estudio cualitativo, cuantitativo y descriptivo, con el objetivo general de comprender el significado del amor, para diferentes actores sociales, en diferentes contextos. Los objetivos específicos son: identificar a los líderes de los ámbitos social, comunitario, empresarial y religioso del territorio de investigación como actores sociales; identificar las características más comúnmente atribuidas y/o asociadas con la palabra amor por diferentes actores sociales y comparar posibles similitudes y diferencias en los significados de amor para diferentes actores sociales. Los resultados de la investigación mostraron que a pesar de que los significados del amor están relacionados con la experiencia de vida de cada participante, todos coincidieron en que es un sentimiento positivo, y para la mayoría, el sentimiento más importante en la vida, por lo que se puede pensar que al ser el amor una experiencia única que permite hacer presente la subjetividad, su presencia favorecería una descentralización de la atención hacia lo externo, y la exacerbación de los afectos y sentimientos negativos, construyendo relaciones sociales más sólidas y significativas, por lo tanto, las discusiones sobre el "amor" son de gran importancia para el desarrollo de subvenciones a propuestas de fomento de los valores morales.
\end{abstract}

Palabras clave: Amor; Sentimientos; Emociones; Relaciones sociales.

\title{
1. Introdução
}

Escrever sobre o amor não é nada simples, pois é um tema complexo, ao mesmo tempo antigo e atual. Todos nós já sentimos "amor" em algum momento de nossa vida, dessa forma, o termo amor é utilizado livremente no nosso cotidiano. Diferentes livros, séries, filmes, poesias, músicas tratam sobre este sentimento, na qual uma indústria completamente dedicada expressa este tema que desperta o interesse na maioria das pessoas.

Mas afinal, o que é o amor? O que nos faz amar alguém ou alguma coisa? O que desencadeia este sentimento em cada um de nós? O que acontece no nosso corpo quando amamos? Que sentimento é esse que faz com que pessoas desconhecidas uma das outras se aproximem e desejem construir uma vida juntas? Essas e muitas outras perguntas são desencadeadas quando refletimos sobre este assunto, mas com toda certeza são questões que não serão respondidas nesta pesquisa, ou em outras, no entanto, mesmo sem termos respostas foram elas que nos impulsionaram a tentar compreender um pouco deste sentimento, principalmente quando pensamos em diferentes atores sociais.

Falar sobre amor traz à tona demandas que envolvem historicidade, os motivos que nos impulsionam a sua busca e a influência deste sentimento para nossa qualidade de vida e bem-estar. De acordo com Maia (2014) são muitas as pesquisas sobre sentimentos como angústia, alegria, tristeza, paixão, que apontam estes como "agentes motivadores do agir do homem em determinadas situações" (p. 3). O amor é um destes sentimentos pesquisados que vai transformar e influenciar o comportamento humano de maneira positiva ou negativa.

Bystronski (1995) reforça essa ideia, trazendo que uma das maiores fontes de felicidade são os relacionamentos satisfatórios. Por isso, o amor é um sentimento que se faz presente de maneira frequente em nossas vidas, pois amamos nossos pais, amigos, cachorros, ídolos, parceiros, entre outros. Assim, de acordo com Maia (2014):

Certamente o amor ocupa uma posição fundamental e essencial na vida humana, pois o homem, de certa forma, é um ser incompleto se não consegue sentir ou praticar este sentimento. A ausência do amor na vida humana afeta totalmente a estrutura deste ser complexo, seja na área física, emocional ou espiritual, pois certamente o amor está presente de forma ativa nestas esferas da vida humana (p. 2).

Com tudo, como definir o amor? Podemos perceber que o tema é instigante, estudado e falado historicamente e em várias áreas do conhecimento. Entretanto, mesmo amando diversas vezes e de diferentes formas, não há um consenso sobre sua definição e entendimento. No dicionário online Michaelis (2021, s.p.) o amor é um "sentimento que leva uma pessoa a desejar o que se lhe afigura belo, digno ou grandioso"; "grande afeição que une uma pessoa a outra, ou a uma coisa, e que, quando de natureza seletiva e eletiva, é frequentemente acompanhada pela amizade e por afetos positivos, como a solicitude, a ternura, o 
zelo, etc.; afeto, devoção".

Pensando em uma breve historiografia do amor, compreendemos a experiência amorosa como um acontecimento dinâmico influenciado pelos contextos históricos que levam em consideração diferentes concepções de amor. De acordo com Pretto et al. (2009, p. 396) "é possível perceber as diferentes configurações de amor produzidas pelos clássicos, pelo cristianismo, pela sociedade de cortesia (séc. XII), pelo amor-paixão romântico (XVIII-XIX) e pela contemporaneidade". De acordo com os autores, o Banquete de Platão foi o primeiro tratado filosófico sobre o amor. Na obra são apresentados seis discursos que definem o amor, o primeiro proferido por Fedro, que traz este como lugar central, para ele Eros é o mais antigo dos deuses, sendo o amor um sentimento que desperta o que há de melhor no ser humano; no segundo discurso proferido por Pausânias, para ele não existe um Eros, mas dois, que seriam duas formas de amor: a etérea e a carnal; no terceiro discurso proferido por Erixímaco, defende o amor saudável, na qual busca o equilíbrio das forças do bem e do mal; no quarto discurso proferido por Aristófanes, seu relato traz sobre a existência de três gêneros: masculino, feminino e andrógino, estes eram inteiramente autossuficientes, mas foram partidos ao meio pelos deuses, sendo condenados a infelicidade eterna por não serem mais completos, ansiando por outra metade; quinto discurso proferido por Ágaton, traz que o amor seria o Deus mais jovem, marcado por uma extrema beleza, virtude e superioridade e; por último, o sexto discurso de Sócrates, no qual o amor é desejo e que nós só desejamos aquilo que não possuímos, por este motivo o amor passa a ser carência e procura, a busca por aquilo que não possuímos e o sétimo discurso de Alcibíades que apenas louva o discurso feito por Sócrates.

A noção de amor é, também, influenciada pelo Cristianismo, de acordo com Lins (2012) “os primeiros cristãos passavam o tempo todo preocupados em reprimir seus impulsos biológicos. Como, por mais esforço que fizessem, os impulsos sempre retornavam, eles colocaram a responsabilidade de visões e tentações sexuais no demônio" (p. 119), ou seja, o amor carnal e a sexualidade foram abafados, focando no mistério do amor agápico, trazendo figuras importantes nesta contextualização como Santo Agostinho, São Boaventura e São Tomás de Aquino. Em suma, o amor-agápico domina a mentalidade amorosa da alta Idade Média. No entanto, esses ideais de condenação do desejo e do prazer não se sustentaram por muito tempo.

Já no século XII há uma grande mudança contrapondo este cenário, surgindo o amor cortês, como uma recusa a normas e padrões estabelecidos pela Igreja e pela sociedade, na qual o amor e o casamento passam a não serem mais exceções, assim, $o$ amor seria uma condição para o casamento (Casey, 1992). Desta forma, começaram a existir as histórias românticas que propagavam o amor carnal e reforçavam a imagem do amor proibido. O ideal de amor romântico surgiu pela primeira vez na literatura no mito de Tristão e Isolda, depois nos poemas e nas canções, fazendo com que os sentimentos ficassem cada vez mais exaltados para a própria satisfação dos sujeitos (Jonhson, 1987).

No Renascimento e Idade Moderna (1453-1789), os costumes medievais recatados ainda continuaram, mas a Reforma Protestante ajudou a torna-los menos rígidos. Tiveram grandes artistas e pensadores que trataram da temática amorosa em suas obras como Espinosa, Descartes e Shakespeare, enfatizando o amor romântico. Como se pode observar a concepção de amor sofreu mudanças ao longo da História, principalmente com aspectos que envolvem e associam amor, sexualidade e casamento (Lins, 2012).

Na Idade Contemporânea (1789 - até os dias atuais), de acordo com Lins (2012) o amor romântico foi conservado como o ideal, ocupando lugar central na nossa vida em todos os níveis culturais, da poesia aos romances, incutindo um ideário do amor nas pessoas, por meio das produções. Corroborando, Araújo (2002) traz que ao longo do tempo criaram-se expectativas e idealizações sobre casamento, amor e sexualidade, o que tornou o amor romântico um alento da cultura contemporânea.

Assim, de acordo com Cerqueira e Rocha (2018) vamos percebendo que as concepções do amor foram diversas e influenciadas de diferentes maneiras, além disso, é importante destacarmos que "o conceito de amor é diferente para cada indivíduo, é subjetivo e imensurável e deve ser entendido tendo em mente o espaço histórico e temporal de cada sujeito que vivencia esse sentimento" (p. 13). 
Podemos observar, então, segundo Schoepflin (2004 apud Nascimento, 2019) que há muitos séculos, diferentes concepções de amor têm sido propostas, mas não há ainda um consenso (e, talvez, nunca haja) dada as suas características essenciais de diversidade e subjetividade. Logo, o amor pode ser estudado, mas, não é possível delimita-lo em uma única concepção por todos que tentam compreende-lo. Dessa forma, muitas ideias e pensamentos a respeito do amor são trazidas, desde aspectos positivos e até mesmo, como algo a ser evitado pelas suas consequências negativas.

De acordo com Almeida (2017), por muito tempo se buscou compreender a estrutura do amor com diferentes definições, mas a própria Psicologia, mostrou-se muitas vezes refratária em aceitar estudar o amor como objeto de suas pesquisas, talvez por entender o amor como algo subjetivo e abstrato que não daria qualquer possibilidade de mensurá-lo. Portanto, até a década de 1950, nos estudos da psicologia, as publicações eram incipientes, relacionadas na maior parte das vezes com o amor entre mães e filhos. Já segundo Maia (2014), as definições do amor são paradoxais, enquanto algumas se limitam a questão sexual, outras abordam apenas as questões comportamentais, nas quais apesar das divergências de diferentes autores como Freud, Hatfield, Altini e Carl Jung, todos concordam que "o amor é fundamental para a formação, desenvolvimento e relacionamento humano" (p. 202).

As possibilidades e teorias para compreensão sobre o amor são diversas, no entanto, algumas teorias se destacam. Inicialmente a teoria de Rubim (1970), que buscou diferenciar o amar e o gostar e, a partir dela, foi consolidado que o amor poderia ser conceituado e mensurado, dando suporte para o desenvolvimento de avaliações. Temos a teoria Triangular do Amor de Sternberg (1986) que é considerada uma das mais bem-sucedidas e completas teorias para estudar o amor, devido à sua generalidade ao ser empregada em diferentes culturas, a qual propõe explicar o amor por meio dos sentimentos vivenciados dentro da relação e que vão promover o vínculo dos parceiros. Stenberg propõe sete tipos diferentes de amor: gostar, paixão, amor vazio, amor romântico, amor companheiro, amor inconsequente e amor consumado, que podem ser alterados de acordo com o momento histórico, espaço geográfico e cultural (Silva et al., 2013).

Já a teoria tipológica do amor, também conhecida por “As Cores do Amor" desenvolvida por John Alan Lee (1974) tenta explicar o amor por meio de uma analogia com as cores. Partindo do pressuposto de que, como nas cores, no amor também encontramos variações, portanto, define seis estilos de amor nos quais as pessoas possuem um estilo predominante em suas relações, divididos em dois grupos, sendo três cores primárias que são Eros (baseado no amor erótico, na qual as pessoas possuem expectativas relacionadas mais aos aspectos físicos e sexuais), Storge (relacionamento mais companheiro e amigável, surgindo da familiaridade e as semelhanças) e Ludus (amor mais descomprometido, onde as pessoas possuem parceiros simultâneos e estão sempre em busca de prazer) e os tipos secundários que são formados pela combinação de dois estilos primários: Ágape (Storge + Eros, que se baseia em um amor mais respeitoso e dedicado, com ausência de egoísmo e presença de cuidado e preocupação com o outro), Mania (Ludus + Eros, que se caracteriza pela preocupação obsessiva com a outra pessoa, as características mais presentes são insegurança, possessividade e ciúme) e Pragma (Storge + Ludus, que se baseia em interesses comuns, valorizando a compatibilidade) (Gouveia et al., 2009; Gouveia et al., 2013).

Já a teoria dualista do amor de Hatfield (1988) propõe dois tipos de amor: o amor companheiro e o amor apaixonado, enquanto o amor companheiro está mais relacionado a sentimento de cuidado e afeto, sendo um amor mais maduro e comprometido, na qual os parceiros compartilham valores e fraquezas; o amor apaixonado volta-se aos aspectos da sexualidade, com variações de emoções fortes, tanto negativas quanto positivas, neste tipo de amor a separação pode provocar muita ansiedade ou desespero (Hernadez \& Oliveira, 2003).

Outra contribuição para o estudo do amor foi a do psiquiatra e psicanalista inglês John Bowlby (1907-1990), que a partir dos anos de 1956, buscou examinar as implicações sobre a maneira com que as crianças enfrentam à perda temporária da mãe. Assim, propôs a Teoria do Apego, que de acordo com Abreu (2005 apud Vasconcelos, 2013), Bowlby tinha como objetivo compreender as possíveis influências adversas no desenvolvimento da personalidade e a falta de cuidados maternos adequados 
nos primeiros anos de vida. Segundo a Teoria do Apego a ausência de um vínculo afetivo seguro pode-se desencadear na vida da criança consequências imensuráveis, portanto, quanto mais seguras forem as relações durante a infância, mais provável será de se tornar um adulto seguro, autoconfiante, conseguindo se relacionar melhor afetivamente.

Outra teoria do amor é a do psicólogo e sexólogo John Money (1986 apud Almeida, 2017) que postulou que as pessoas desenvolvem o que ele chamou de mapa amoroso, que seria o mecanismo pelo qual as pessoas são atraídas por alguém em particular. $\mathrm{O}$ autor espera que as crianças constroem esses mapas entre os cinco e oito anos de idade, aproximadamente, dessa maneira, com o passar o tempo, estes vão ter influência sobre o interesse afetivo sexual dos sujeitos e por que se apaixonam por uma pessoa e não por outra, ou seja, pessoas que mais se encaixam no ideal do mapa de amor, que seria consultado milhares de vezes durante a vida. Com tudo, as transformações continuam ocorrendo na nossa sociedade e influenciando de maneira constante as nossas relações afetivas e a forma como vamos vivenciando nossas emoções e sentimentos.

Já Bauman (2004), traz em sua obra "Amor Líquido: sobre a fragilidade dos laços humanos", a dificuldade de se perpetuar os vínculos. "A misteriosa fragilidade dos vínculos humanos, o sentimento de insegurança que ela inspira e os desejos conflitantes (estimulados por tal sentimento) de apertar os laços e ao mesmo tempo mantê-los frouxos” (p. 8). No texto, o autor vai relatando sobre as mudanças nos relacionamentos, fazendo comparações sobre o comportamento nas relações humanas com o consumismo capitalista. $\mathrm{O}$ autor integra a ideia de rapidez com a ideia de liquidez e apresenta como exemplo deste processo a globalização. Sua intenção é demonstrar como a modernidade transformou a maneira como as pessoas se relacionam no chamado mundo pós-moderno. Na qual a ideia que predomina anteriormente sobre amor romântico e idealizado de viver com a pessoa "perfeita" pelo resto da vida não cabe mais nos dias atuais. "Noites avulsas de sexo são referidas pelo codinome de 'fazer amor"” (p. 16), portanto, na contemporaneidade pensar em desfrutar uma vida com alguém já não é mais tão significativo como antes, o que prevalece é a vontade de estar junto e ao mesmo tempo não estabelecer relações duradouras, uma completa ambivalência que resulta em instabilidade e incertezas.

De acordo com Reichow (2015) vivemos em uma sociedade onde os sujeitos não querem sofrer, o narcisismo prevalece e o indivíduo se preocupa excessivamente consigo e com o seu corpo, desprezando o outro e se importando apenas em viver os momentos, assim,

Não há qualquer tipo de garantia. A "fixação" e a "flutuação" medeiam, cada uma a seu modo, a tênue fronteira entre segurança e dependência (como um tipo de possessão/ escravidão) por um lado e liberdade e insegurança, por outro. Esses extremos, em torno dos quais podem ser situados os relacionamentos, são responsáveis pela ambivalência que caracteriza o amor (Guedes, 2005, p. 355).

Existindo, de acordo com Almeida (2017), uma fragilidade sobre os relacionamentos contemporâneos, aqueles relacionamentos duradouros e consistentes deixaram de existir na sua maioria e os relacionamentos atuais não têm necessidade de fidelidade, só se mantendo enquanto os parceiros proporcionarem apenas satisfações. Por isso, o divórcio que era raro, hoje é algo natural, até mesmo as traições que antes eram menos comuns, ficam mais visíveis devido a vasta quantidade de alternativas atraentes disponíveis.

Dessa maneira, de acordo com Schlosser (2014) as relações podem ser compreendidas como fator de proteção ou de risco, diretamente envolvidas no processo saúde-doença. Portanto, mesmo o amor sendo considerado positivo e idealizado, existem os dois lados. Os fatores de proteção seriam relacionados aos sentimentos e comportamentos que as relações podem contribuir na qualidade de vida dos sujeitos, já os fatores de risco, que podem ser gerados pela ruptura de uma relação ou desentendimentos, ou seja, dificuldades e adversidades que perpassam as relações, são aspectos negativos que geram intensos sofrimentos.

Com todas essas informações, nos parece que a única forma de amar seria entre casais, no entanto, é importante 
frisarmos que existem muitas outras maneiras de amar e demonstrar este amor, como o amor que sentimos por um amigo, membros da família, animal de estimação ou parceiros que se fazem presente em nossas vidas, por exemplo. Por isso, todas estas relações são importantes e necessárias para todos.

O escritor e psiquiatra, Doutor Marco Aurélio Dias da Silva (2014) traz em seu livro "Quem ama não adoece”, a importância do amor para a saúde e qualidade de vida das pessoas, na qual é necessário um autoconhecimento para entendermos nossas potencialidades, tristezas, falhas, e assim, descobrir os reais sentimentos e pensamentos que somamos ao longo de nossas vidas, onde se não cuidados transformam-se em doenças, por isso, o objetivo é um maior equilíbrio para conseguirmos alcançar nosso bem-estar. Corroborando, Almeida (2017) apresenta o amor como um sistema complexo e dinâmico, que vai envolver desde a cognição e emoção, até comportamentos de felicidade e a qualidade de vida.

Vimos que existem diferentes compreensões sobre o amor, mas todas interferem na vida dos sujeitos, de maneira positiva ou negativa.

Para a Terapia Ocupacional, enquanto uma profissão que entende a importância da compreensão do comportamento humano, no qual as relações, emoções, sentimentos e afetos se fazem presente no cotidiano e, consequentemente, podem impactar na saúde e bem-estar dos sujeitos, torna-se importante estudar e compreender melhor este tema.

Para Papini (2011) o terapeuta ocupacional tem uma:

Posição privilegiada, podendo contribuir para a visão de cotidianidade do sujeito, seja em ações práticas, como na elaboração mais crítica de concepção desse sujeito, seja pela ampliação de um olhar que possa trazer à tona questões concernentes à (re)significação, possibilitando a compreensão da subjetividade e realidade pessoal (p. 81).

Com isso, segundo Oliveira (2013) é importante que exista o acolhimento de todas as implicações do sujeito, considerando suas subjetividades e valorizando as necessidades em conjunto com o saber clínico do profissional. O que permite ao terapeuta ocupacional, por exemplo, facilitar a expressão dos sujeitos.

Sabemos que, algumas vezes, existe a dificuldade de compreendermos e expressarmos nossos sentimentos de forma clara, por isso, na terapia ocupacional, durante todo o processo terapêutico, os sentimentos, afetos e as emoções são valorizados e trabalhados para que os sujeitos consigam elaborá-los de forma mais clara e consciente. A análise das características subjetivas e individuais de cada um, na terapia ocupacional, busca fortalecer o autoconhecimento, estruturando o cotidiano e a rotina, proporcionando trocas e experiências consigo mesmo, com o terapeuta e com o outro.

Do mesmo modo, Papini (2011) traz que "as necessidades de cada um tornam-se conscientes para o sujeito, a partir do olhar para seu próprio EU; neste caso, percebe-se que, quando o cotidiano é valorizado, valoriza-se também a singularidade, a subjetividade de cada um, motivando-o para as ações" (p. 82). Mais uma vez, percebemos o quanto conhecer as emoções, sentimentos e afetos, no caso deste estudo "o amor" é importante na terapia ocupacional, pois compreendendo o eu, acolhendo suas particularidades, desde potências até fragilidades e sofrimentos, as ações cotidianas e "o fazer" vão sendo incentivados, permitindo que o sujeito volte a ser protagonista de sua história.

Portanto, o terapeuta ocupacional a todo momento traz o cotidiano dos sujeitos, reconhecendo suas emoções, suas histórias, crenças e cultura, aspectos estes relevantes e necessários no seu dia a dia. E, a partir desse cotidiano, trazido por nossos sujeitos durante as atividades realizadas na terapia ocupacional, é "possível contribuir para um pensamento de práticas voltadas à emancipação, pois, quando há uma valorização, tende a ser mais do que um simples dia a dia, a construção de uma história" (83). Este profissional investiga hábitos e rotinas, em que as emoções, os afetos e os sentimentos precisam ser compreendidos, sendo questões que vão para além das demandas ocupacionais de cada sujeito, mas, que se fazem presente, influenciando o dia a dia de todos nós e com isso, influenciando nossa história de vida. 
Nesse contexto, é importante que as informações obtidas sejam construídas e apreendidas diariamente para que se tenha uma visão acolhedora sobre o significado de todas essas questões, em especial a que estamos trazendo aqui, o "amor", pois assim, iremos compreender o valor que está assumindo na experiência de vida dos sujeitos e como interage com suas áreas de ocupação. Deste modo,

Falar sobre cotidiano é, também, dizer sobre histórias de vida; se você é personagem de uma história, quem é o autor dessa história? Nas histórias da vida real, não existe autor da história, será que não são todos os personagens que montam as histórias, a História? Todos nós, eu, você, as pessoas com quem convivemos, somos os personagens de uma história que nós mesmos criamos, fazendo-nos autores e personagens ao mesmo tempo. Assim, a partir das e nas escolhas, durante o processo das atividades humanas, ações humanas, objetiva-se a construção de sujeitos históricos, capazes de aprender sobre sua dada realidade e agir sobre ela (Papini, 2011, p. 84)

Nesse prisma, a singularidade do sujeito e as "particularidades do social nos conclamam a compreender no lugar de explicar, subjetivar em vez de replicar, de transgredir para crescer" (Araújo et al., 2014, p. 17). Percebendo que, em meio ao cotidiano dos sujeitos, uma história vai sendo construída, narrada ou vivida, e suas relações com as emoções e sentimentos vão se dando no caminho percorrido, nas suas diferentes formas e intensidades, revelando a diversidade e a subjetividade, revelando modos de vida.

Assim, o objetivo geral desta pesquisa é compreender o significado de amor, para diferentes atores sociais, em contextos diversos. Enquanto que os objetivos específicos são: identificar líderes de esferas sociais, comunitárias, empresariais e religiosas no território de pesquisa como atores sociais; identificar características mais comumente atribuídas e/ou associadas à palavra amor por diferentes atores sociais e comparar as possíveis semelhanças e diferenças dos significados de amor para os diferentes atores sociais.

\section{Percurso Metodológico}

Trata-se de uma pesquisa qualitativa, quantitativa e descritiva, com a finalidade de conhecer os significados de amor para diferentes os atores sociais em suas culturas (crenças, valores, conhecimentos, cotidiano e práticas). A pesquisa qualitativa foi escolhida pois responde a questões muito particulares, além de se preocupar com um nível de realidade que não pode ser quantificado, trabalhando assim, com o universo de "significados, motivos, aspirações, crenças, valores e atitudes, o que corresponde a um espaço mais profundo das relações, dos processos e dos fenômenos" que possuem um lado não captável em equações médias e estatísticas (Minayo, 2001, p. 21).

A metodologia quantitativa foi realizada pela análise descritiva de dados pessoais, socioeconômicos e demográficos como sexo, idade, estado civil, residência em zona urbana ou rural, entre outros, em questionário elaborado pelas pesquisadoras. Estudos descritivos descreverem uma realidade sem tentar explica-la ou tão pouco intervir, sendo importante quando poucos estudos com o tema foram realizados (Aragão, 2011).

\subsection{Local da Pesquisa}

Devido ao período de crise sanitária da Pandemia ocasionada pelo novo Coronavírus - COVID-19, com consequente adaptações nas atividades de ensino, pesquisa e extensão, esta pesquisa foi realizada de maneira remota por meio da plataforma Google-Meet e formulários online pelo Google-forms.

\subsection{Participantes da Pesquisa}

A amostra foi por conveniência a partir da estratégia snowball com recrutamento em redes sociais, organizações representativas e mídias sociais. Foi realizado um mapeamento de líderes (sociais, comunitários, culturais, políticos, empresariais 
e religiosos), a partir de comunidades em redes sociais, contato com representações e associações por meio de telefone e/ ou email. Para esta pesquisa totalizou dezoito participantes. Como a amostra foi por conveniência. Foram incluídas pessoas de ambos os sexos, com dezoito anos ou mais de idade, líderes sociais, comunitários, culturais, políticos, empresariais e religiosos.

\subsection{Aspectos éticos}

A principal questão ética dessa pesquisa refere-se à garantia de anonimato dos participantes, em todas as publicações decorrentes da mesma, sendo compromisso assumido pelas pesquisadoras. A presente pesquisa faz parte do projeto de pesquisa "A Essência Humana: sentimentos, emoções e afetos, uma viagem pela vida sob o olhar de diferentes atores sociais", só foi executada após aprovação do Comitê de Ética e Pesquisa, CAAE: 29943520.9.0000.5546, processo n4.490.562. Para participar da pesquisa os participantes preencheram o Termo de Consentimento Livre e Esclarecido online (TCLE), clicando na opção que afirma que concordavam em participar da pesquisa. No TCLE estavam explicitados os objetivos da pesquisa, o formato de coleta de dados, a garantia do anonimato e a forma de utilização dos dados provenientes da investigação.

\subsection{Instrumentos e Procedimentos de Coleta de Dados}

A coleta de dados foi feita em dois momentos após a assinatura do TCLE. Primeiro por meio do emprego de um questionário (APÊNDICE B) com dados pessoais e sociodemográficos, como idade, profissão, estado civil, naturalidade, religião, o qual foi feito de maneira remota (https://forms.gle/btYmoNbaZcQwyzTj8).

O segundo momento foi realizado por meio de uma entrevista aberta em plataforma digital (GOOGLE-MEET). Foi agendado dia e horário com a disponibilidade dos pesquisadores e participantes, para uma entrevista aberta, de maneira individual, permitindo que os mesmos falassem de maneira livre, a respeito das questões abordadas a partir de suas experiências cotidianas, culturais e contexto em que se encontram. Para este estudo foi perguntado: “Qual o significado de amor para você?"

\subsection{Análise dos Dados}

As entrevistas foram gravadas na íntegra para fins, exclusivamente, da pesquisa. Foi priorizada a análise qualitativa dos dados, por isso utilizou-se de referências quantitativas em números e percentuais apenas para o auxílio na apresentação dos participantes.

Tendo o material das entrevistas gravado e transcrito, foram realizadas leituras "flutuantes", com o intuito de familiarizar com os conteúdos, tomando contato com os documentos a serem analisados, conhecendo o contexto e deixando fluir impressões e orientações. A partir das leituras flutuantes foram emergindo temas diversos, que se caracterizavam pela maior frequência (pela sua repetição ou reiteração), importância que os sujeitos traziam nas falas, pela carga emocional presente e pelas ambivalências ou contradições (Aguiar \& Ozella, 2006).

Os dados quantitativos foram transferidos para uma planilha do excel e analisados a partir do software Statistical Package for the Social Sciences - SPSS versão 22.1. Para análise dos dados, na fase descritiva, foram usados números brutos, frequências simples e porcentagens.

A análise dos dados qualitativos surge a partir das respostas da pergunta: “Oual o significado de amor para você??"

\section{Discussões e Resultados}

\subsection{Caracterização dos Participantes}

No decorrer da pesquisa os participantes foram nomeados em participante 1, participante $2 \mathrm{e}$, assim, sucessivamente, para preservação do anonimato. Dentro os dezoito participantes da pesquisa, 22,2\% eram mulheres e $77,8 \%$ homens, sendo que nenhum deles possuía deficiência. Com relação a raça/etnia 33,3\% eram brancos, $27,8 \%$ negros, 33,3\% pardos e 1,6\% eram 
outros. Relacionado a escolaridade 5,6\% tinha o ensino fundamental incompleto, 11,1\% com ensino fundamental completo, $11,1 \%$ com ensino médio incompleto, $5,6 \%$ com ensino médio completo, $16,7 \%$ com ensino superior incompleto e $50 \%$ com ensino superior completo.

Já com relação ao trabalho $66,7 \%$ se apresentavam ativo no mercado de trabalho, $11,1 \%$ desempregados e $22,2 \%$ aposentados, sendo que a renda mensal variava entre menos de um salário mínimo 5,6\%, um salário mínimo 22,2\% e acima de um salário mínimo $72,2 \%$. No aspecto moradia $83,3 \%$ moravam na zona urbana e $16,7 \%$ na zona rural, a maioria morando com outras pessoas $88,9 \%$. A religião dos participantes variou entre 44,4\% católica, umbanda 5,6\%, Santo Daime 5,6\%, espírita 5,6\%, Candomblé $5,6 \%$, Wicca $5,6 \%$, Ateu $5,6 \%$ e outros $22,2 \%$.

\subsection{Análise das entrevistas}

Dando continuidade ao processo de compreensão dos significados de amor apontados pelos participantes desta pesquisa, inicia-se o processo de apropriação do conteúdo das entrevistas para assim chegar a organização de temas que nos permitiram alcançar os pontos centrais para nossa análise.

\section{$1^{\circ}$ tema: O caminho do amor: "Por onde andei, enquanto você me procurava...” (NANDO REIS)}

Será possível, então, um triunfo no amor? Sim. Mas ele não se encontra no final do caminho: não na partida, não na chegada, mas na travessia (Rubem Alves).

Segundo Cerqueira e Rocha (2018) historicamente, o amor e os relacionamentos amorosos ocupam diferentes importâncias para a vida social, assim, as concepções do amor foram se modificando de acordo com o momento histórico, social e cultural, por isso não existe uma concepção única ou ideal de amor, os estilos vão se transformando com o tempo e contexto, além de se diferenciar de acordo com cada sujeito que vivencia e experimenta este sentimento. Portanto, o amor é "complexo, porque dele fazem parte uma complexidade de sentimentos" e determinantes históricos, sociais, culturais e subjetivos (Thums, 1999 apud Silva, 2002, p. 42).

De acordo com Domingues (2013), apesar do amor ter sofrido modificações no decorrer da história, ele permaneceu presente como um sentimento de grande importância em todos lugares, épocas, povos e contextos. O autor traz que Pires (1978) em seu livro "Pesquisas sobre o Amor" vem discutindo sobre essa evolução e transformação do amor, desde o amor primitivo, como uma simples relação instintiva e intuitiva entre machos e fêmeas. Depois, com a evolução da espécie, apresenta o amor "como um elemento já existente no consciente psíquico [...]" (p.27). Assim, podemos perceber que o amor, mesmo nas suas diferentes formas de apresentação, continua a ser tema de pesquisas, estudos e questionamentos, se fazendo presente em todas as pessoas, independente da cultura, religião, época e classe social. Mas "o que é amor? Será possível explicar em palavras esse termo completamente subjetivo?" (Domingues, 2013, p. 11).

"[...] amor? Amor é assim, algo que a gente se apaixona, né? Que a gente sente de coração mesmo. Que a gente ama (...) que a gente gosta, então, para mim, isso é amor, algo que a gente se apega por de dentro da alma [...]" (Participante $1)$.

Portanto, como as emoções se fazem presente dentro de nós e nos envolvem em múltiplos aspectos, elas vão refletir no nosso funcionamento como um todo, tanto de maneira positiva como negativa, influenciando até mesmo nos aspectos biológicos. De acordo com Bock, Furtado e Teixeira (2001 apud Gimenez \& Bervique, 2006) o corpo tem ligação com as emoções, deste modo, um efeito físico reflete de maneira emocional e vice-versa. 
Nesta pesquisa, observamos que o significado de amor, trazido pelos diversos atores, se mostrou enquanto plural dentro do contexto e cultura que estão inseridos, caracterizando enquanto um processo contínuo de aquisição de sentimentos, afetos, entre outros, e que envolve múltiplos determinantes, todavia, todos os participantes trouxeram o "amor" como um sentimento que está relacionado a aspectos positivos e que precisa ser mais cultivado entre nós.

Por isso, podemos pensar no amor relacionado a outros aspectos positivos, como por exemplo, a felicidade. Cerqueira e Rocha (2018) trazem essa relação do amor com a felicidade, onde encontrar um parceiro ao longo da vida é comparado muitas vezes a busca por ter felicidade, pois para muitas pessoas isso seria uma forma de completude. Como descreve Platão em "O Banquete" no qual diz que "o amor é o mais antigo dos deuses, mais poderoso e honrado para conquista da felicidade e virtude entre os homens, tanto na vida, como após a morte" (Domingues, 2013, p. 11).

"[..,] amor é a pessoa ter seu marido, é querer muito bem a ele, porque eu já tenho 53 anos de casada com meu "veinho", tenho muito amor por ele, e nós só vai se separar quando eu se for e ele, em nome de Jesus (risos), pois é ele que me dá força [...]" (Participante 2).

Assim, Martucelli (2016, p. 148) traz que, "seja como for, é em nome desse ideal - devidamente traduzido e assumido pelas obrigações morais parentais - que muitos homens e mulheres encontram força, todos os dias, para se levantar e ir trabalhar". O autor chama atenção para o "crescente consenso em torno da legitimidade fundamental do amor como algo prenhe de sentido da vida" (149).

"[...] acho que é um sentimento que nos move, que nos impulsiona a proteger a outra pessoa, a nos proteger, de se reenergizar a cada dia, de nos fazer caminhar, de não nos deixar parado [...] o que dá sentido na nossa vida [...]" (Participante 5).

De acordo com Schlosser (2014) estes aspectos positivos que relacionam a necessidade de amar para se obter uma felicidade ou ter um companheiro para se sentir completo, podem ser vistos em muitos locais como: frases, novelas, músicas, filmes, obras de arte, os quais enfocam o amor como uma das mais importantes causas da felicidade, da qualidade de vida, dentre outras questões que vão compor os aspectos positivos da nossa existência.

Entretanto, nem sempre isso é verdade, pois para alguns pode ser necessário ter um relacionamento amoroso, mas para outros não, dessa maneira, percebe-se mais uma vez a questão subjetiva presente, pois cada sujeito apresenta um tipo de necessidade a partir da maneira com que foi criado, pela sua cultura e contexto que se encontra (Cerqueira \& Rocha, 2018).

Assim, percebemos que as relações sociais, que fazem parte da vida de todos nós, são permeadas de emoções e sentimentos conscientes ou inconscientes, mas principalmente subjetivos (Silva, 2002), e que a maneira com que vamos aprendendo estes sentimentos, inclusive o que é amor, é na infância dentro de nossas casas, com nossa família, mas a maneira com que vamos amar futuramente não será apenas uma repetição de como fomos amados ou nos ensinaram a amar (Alves; Alencar \& Ortega, 2012). De tal modo, poderíamos pensar: Será que:

Existe um conceito pré-definido que nos ensine a amar? E amar o que? Somos ensinados desde pequenos a amar isso ou a amar aquilo, a amar alguém ou a não amar alguém, amar muito ou pouco, dessa ou daquela maneira, tais ensinamentos que se distinguem conforme cultura, e modificam-se conforme o passar do tempo, mas sempre de acordo com as relações sociais estabelecidas pelas próprias pessoas que são produtos e ao mesmo tempo produtoras dentro do meio em que se encontram (Domingues, 2013, p. 11).

Essas modificações acontecem principalmente porque o amor se modifica ao longo dos tempos, ou seja, é uma construção sócio-histórica, sendo atravessado por determinantes sociais e culturais, permitindo que sua compreensão se faça de 
diferente maneiras e que cada pessoa possa experimenta-lo e entende-lo de maneira subjetiva de acordo com a época e contexto vigente (Beraldo, 2018).

No entanto, Beraldo (2018) traz que mesmo os mais diferentes posicionamentos de Freud sobre o amor, não são, na sua maioria, excludentes, mas complementares e o que mais marca sua teoria sobre este sentimento seria "sua impossibilidade de realização, é essa falta que corrói o peito dos amantes e que nunca pode ser aplacada, pois não existe o objeto último do desejo que acalmaria as angústias existenciais do homem, completando-o, fazendo-o" (p. 36) alcançar uma felicidade dita como plena e perfeita, tão buscada nos tempos atuais. Assim,

O amor é, inevitavelmente, um contínuo procurar, um contínuo perder-se e um contínuo reencontrar-se. A principal dificuldade em relação ao sentimento amoroso não está em vive-lo, mas em mantê-lo. O amor aparece e desaparece, nasce e morre e não podemos adivinhar o tempo que permanece em nós. As dificuldades na definição do amor resultam, além da natureza contraditória, também desta direção transformativa instável, porque o amor é mudança e raramente estabilidade (Marques, 2001, p. 81).

Com isso, para Beraldo (2018) amar é manter-se o tempo todo perseguindo um prêmio que nunca poderá ser alcançado, assim, viver este sentimento é permanecer em uma dualidade marcada por glorias e infortúnios, ou seja, um viajar por um caminho que não tem fim, mas que tem diferentes perspectivas, acontecimentos, sofrimentos, conquistas e significados.

\section{$2^{\circ}$ Tema: $\mathrm{O}$ sentido do amor: “Quem inventou o amor? Me explique por favor...”(Renato Russo)}

O amor é tudo que temos, o único caminho pelo qual um pode ajudar o outro [...] (Eurípedes).

O autor Beraldo (2018) traz o amor representado pelo cuidado, ou seja, doar nas ações e zelo com o outro, se colocando à disposição e servindo, pois, para o amor nesta perspectiva, o objetivo maior é ver o outro bem.

\section{"[...] amor é uma pessoa querer bem a outra [...]" (Participante 2). \\ "[...] um amor verdadeiro é aquele que não prejudica ninguém, que quer o bem-estar um do outro [...]" (Participante 4).}

Como afirma Marques (2001, p. 80) "o amor mobiliza sentimentos de entendimento e cuidado pelo outro". Corroborando, Bastos (2016) define "o ato de amar como sendo a entrega ao outro" (p. 46).

"[...] é se doar. Para mim amor é você se entregar, é você se doar por alguém, por uma causa, é cuidar, proteger [...]" (Participante 12).

Assim, "a prática do amor defende o indivíduo do egoísmo porque é uma tarefa que se direciona ao outro [...]. A prática surge para salvaguardar o ser humano desta condição de solitude, justamente porque ela coloca o ser humano na tarefa com o outro" (Bastos, 2016, p. 32).

“[...] amor para mim é uma ação, amor para mim não é um sentimento, amor é uma disposição em dar, em se doar, tanto para si quanto para o próximo [...]”" (Participante 6)

Dessa maneira, percebemos que ao mesmo tempo que as definições e falas trazem sobre o cuidado, a dedicação e a entrega ao outro. É possível perceber, também, a importância do amor a si próprio. Marques (2001, p. 82) traz a fala de Erich Fromm (1992) na qual "amar é dar, logo a felicidade advém do próprio ato de dar que expressa vitalidade, poder, genialidade, descobrindo-se o amor por si próprio na experiência de descobrir que se possuem estas qualidades no ato de amor”. O autor fala 
que Erich com esta síntese tenta "afirmar que, em qualquer relação amorosa, estão sempre presentes três dimensões: o amor ao outro, o amor à relação e o amor a si próprio" (p. 82).

“[...] primeiro de tudo a gente tem que que ter amor próprio, a partir do momento que você se ama, você passa a saber amar outras pessoas e respeitar, entendeu? [...]” (Participante 3).

De acordo com Bastos (2016) a pessoa que está amando passa por um processo de transformação pessoal, assim "sua relação consigo, com o outro, com o mundo, ganha um novo sentido, a saber, o sentido amoroso" (p. 46). Por isso, o autor coloca que o sujeito precisa estar consciente do amor, para permitir essa transformação interior, "afirmando o a si mesmo" e depois, "colocando-se para o próximo, enquanto tarefa" (p. 39)

Portanto, com essas possibilidades de crescimento interno e externo, podemos pensar no amor como uma das emoções mais intensas e, também, uma das mais buscadas pelas pessoas e por diversas áreas do conhecimento (Hernandez et al., 2014).

"[...] amor é uma potência que o ser humano tem, senão for a maior potência, é uma das maiores [...]” (Participante 4).

"[...] amor eu acho que é uma das principais virtudes do ser humano [...] talvez, o sentido da vida [...]” (Participante 4).

Martuccelli (2016) em seu artigo "O indivíduo, o amor e o sentido da vida nas sociedades contemporâneas", traz que na atualidade vem acontecendo um aumento da racionalização e do controle das pessoas e com isso a perda do sentido da vida. Dessa maneira, o autor questiona como, por que e em que medida o amor acabou tornando-se o principal apoio de sentido individual. Assim, ele alega que na vida moderna, o amor seria tanto o ideal como uma das maiores promessas de felicidade, sendo este amor apresentado de diferentes formas, conjugal, de amizades, ou amor de filhos, entre outros. Por isso podemos pensar no amor como,

“[...] um sentimento que nos faz bem [...]que precisa estar presente em todas as nossas ações: amor ao trabalho, amor às pessoas que nós trabalhamos juntos, amor à família, aos filhos, esposa, pai, mãe. Acho que amor é um, é um elo de ligação, de você com aquilo que te cerca [...] o amor é uma coisa boa, um sentimento bom [...] vamos supor que o amor é o oposto do ódio é o elemento da vida [...]” (Participante 8).

Portanto, podemos pensar no amor como um sentimento que vai, geralmente, nos proporcionar satisfação e diferentes valores positivos e prazerosos (Domingues, 2013), trazendo sentido e significado a nossa vida, dos mais simples aos mais complexos acontecimentos e pelas diferentes pessoas que fazem parte de nossa convivência.

"[...] amor? Acho que é um conjunto de várias emoções boas e positivas, acho que é um abraço quentinho, um café gostoso com a minha família [...]” (Participante 13).

Assim, mesmo o amor sendo visto como o sentido da vida, a completude, a felicidade, a maior virtude, o elo de ligação entre as pessoas e se fazendo presente dos mais simples aos mais complexos acontecimentos dos nossos dias, ele não consegue ser explicado ou simplesmente definido na maior parte das vezes, mas consegue ser sentido, expresso e experienciado, como trazido por nossos participantes.

“[...] amor é a maior expressão da vida. Amor é a vida, assim, tudo isso que existe é a expressão desse sentimento que a gente não consegue ainda saber o que é ou explicar. A gente dá nome a sentimentos como afeto, gostar do outro, mas o amor mesmo, é para mim a expressão maior desse movimento. Então, quando a gente conseguir sentir de fato esse movimento dentro da gente, a gente vai estar sabendo o que é amor, até então, eu acho que a gente ainda está precisando despertar para saber [...]" (Participante 9) 
Esta compreensão do amor é importante para nós, pois de acordo com Baptista \& Roldão (2017) trazem que o amor tem sido destacado por diferentes autores como uma das mais importantes fontes de prazer e satisfação, influenciando na saúde mental, emocional e física das pessoas, chegando a ser considerado em alguns estudos como uma das bases que nos faz adoecer ou ter saúde

“[...] amor é tudo, se você tem amor você consegue não ter ansiedade [...]melhora seu ânimo, sua saúde, sua vida [...] o amor é companheirismo, é solidariedade [...] é essa multidão de sentimentos nos quais a gente pode participar, conviver, isso é muito bom [...]" (Participante 11)

Consoante, Braz (2020) apresenta o amor como uma característica própria de cada sujeito, sendo esta capaz de aproximar a pessoa da sua essência, principalmente porque consegue propiciar o desenvolvimento de relações sociais, estruturando a personalidade de cada um. Assim, de maneira poética, Chapman (1997) resume a importância do amor: "sem amor, montanhas tornam-se insuperáveis, mares intransponíveis, desertos insuportáveis e dificuldades avolumam-se pela vida afora" (p.9).

$3^{\circ}$ Tema: Os tipos de amor: "Deixa eu dizer que te amo. Deixa eu pensar em você. Isso me acalma. Me acolhe a alma. Isso me ajuda a viver" (Marisa Monte)

O amor não faz o mundo girar. O amor é o que faz o giro valer a pena (Mariana Nunes)

Para definir amor, Comte-Sponville (1999 apud Alves et al., 2012) propõe três formas: "eros, philia e ágape. Eros é a paixão amorosa, sendo caracterizado pelo desejo do que falta, assim, é sofrimento e carência; é amar o outro para nosso próprio bem. Por sua vez, philia é o amor da amizade é a vontade de fazer o bem um ao outro [...]" (p. 262). Por último, o autor traz o “amor ágape, no qual não se espera nada em troca, sendo, portanto, gratuito. É o amor sublime, pois é amar a todos, inclusive os desconhecidos e os inimigos" (p. 262).

“[...] na nossa língua portuguesa, a gente usa a palavra amor para tudo, praticamente. Se eu for dizer que tenho uma relação de carinho com meu pai, com minha mãe, com alguém da minha família, eu vou dizer que eu amo eles; se eu for dizer a mesma coisa para uma mulher que eи goste, eu vou dizer que tenho esse amor por ela; se en for dizer que tenho uma relação de carinho com meu amigo, eu vou dizer que amo esse amigo; mas quando a gente vai para outras línguas, por exemplo o grego, ele teria uma palavra diferente para falar de cada amor desse: o amor de amigo, vai chamar de philia, o amor do casal, ele vai chamar de eros, o amor divino, ele vai chamar de ágape, então os gregos vão fazer essa distinção [...]”" (Participante 14).

Corroborando, Quadros (2011, p. 165) traz essas três principais acepções do amor na língua grega: "Eros, Fília e Ágape". Comumente, relacionando o primeiro ao amor sexual; o segundo à amizade e o último a um amor espiritual. De acordo com o autor "o amor "Ágape enquanto amor cristão se revela em algumas formas: caridade e misericórdia. Nesse sentido, o exercício desse amor-ágape pressupõe benevolência, complacência, compaixão, indulgência e perdão ilimitados” (p. 169).

"[...] eu entendo o amor como a principal herança que a gente recebe da divindade, nós como filhos e filhas, acho que temos o amor como a principal virtude mesmo, não é à toa que vai estar nos ensinamentos de diversas tradições [...]" (Participante 10)

“[...] o próprio cristo trouxe essa sintese dos mandamentos né, amar a Deus sobre todas as coisas, ao próximo como a si mesmo, como o resumo de todos os mandamentos. E então, eu acho que o amor tem esse papel mesmo bem central, eu acho que dentro da ideia de sermos imagem e semelhança do criador, além da nossa capacidade co-criadora [...]o amor nos unifica, porque eu acho que na medida em que a gente reconhece esse amor como sendo uma presença em todos os seres da criação fica mais fácil da gente reconhecer essa fraternidade universal entre toda a obra da criação e eu acho que o amor ele é esse chamado, esse desafio que a gente tem de reconhecimento da vida divina em cada ser 
dentro dessa possibilidade da gente ser amável, ser amoroso, ser compreensível, se doar, ser solidário [...] todas as coisas que estão dentro dessa virtude nobre tão central que é o amor [...]” (Participante 10).

Com isso, vamos observando em algumas falas um amor mais relacionado aos aspectos espirituais e sagrados. Nesta ideia, Cerqueira \& Rocha (2018) trazem sobre essa concepção do amor sagrado, que seria "algo muito maior e mais altruísta do que buscar a completude em outra pessoa [...] amor no sentido mais total, o amor simplesmente dado, sem esperar por recompensa" (p. 11). Para os autores pensar no amor por meio dessa abordagem seria incluir "a amizade entre Deus e os seres humanos [...] ter o amor de Deus já seria o suficiente para alcançar o propósito do amor, sem precisar de um amor romântico, no sentido de amante" (p. 11). Dessa maneira, podemos pensar em um amor que não espera nada em troca e não julga em nenhum momento aquele que se ama, ou seja, o amor mais puro que uma pessoa possa sentir.

Bastos (2016) vem trazendo a diferença entre um amor puramente humano, que tem como característica básica o egoísmo e a busca da perfeição, e, o amor cristão, que ama o outro com as imperfeições e dificuldades, se doando sem exigir nenhuma reciprocidade. Assim,

A deficiência do primeiro consiste em não querer manter relação caso suas representações de perfeição não sejam atingidas; na medida em que o outro (objeto do amor) demonstrar suas falhas e fraquezas, o amor puramente humano modifica-se e afasta-se levando junto consigo a ideia de perfeição que construiu. A fraqueza da relação não se deve por conta das imperfeições que o outro possui, mas na própria fraqueza do amor que não consegue amar o homem que vê, da maneira como se vê, com suas falhas e imperfeições (p. 45).

Bastos (2016) traz que o amor está enraizado no ser humano, entretanto, Silva (2002) coloca que apesar do amor se fazer presente em todos nós, é importante que tenhamos consciência de nossas emoções e sentimentos e, também, quando possível das emoções e sentimentos do outro, pois desta maneira, os limites de cada um vão sendo descobertos, permitindo que as dificuldades afetivas, cognitivas e cotidianas sejam superadas e, a felicidade possível, seja alcançada. Para o autor, a felicidade seria o resultado de um equilíbrio dessas relações emocionais, tanto do indivíduo com ele mesmo, como com o outro (SILVA, 2002).

Portanto, Domingues (2013) questiona quando relacionamos apenas aspectos positivos ao amor, pois para o autor "nos deparamos na experiência da vida com casos em que se considera que amar demais se tornou maléfico à saúde, ou seja, quando ocorre falta de controle e de liberdade de escolha sobre a conduta de amar" (p. 11), demonstrando mais uma vez a necessidade de termos consciência de nossos sentimentos para que possamos permear o equilíbrio.

"[...]de tanto eu querer que ela me ame, amá-la vai ficar parecendo que é eu faria isso a qualquer custo, eu passaria por cima de alguém, eu agiria de uma forma que é, como se diz, modificaria uma situação, uma circunstância, dando a entender que eu estava fazendo isso por amor [...]" (Participante 4).

Segundo Rios (2008, p. 425) "o amor atrai pela promessa do bem, mas cutuca uma ferida narcísica: expõe nossa carência, nossa falta em sermos completos como gostaríamos. Quando amamos, sofremos porque vemos no outro tudo o que nos falta e queremos". Assim, vamos sofrendo com medo de amar mais que o outro, de sermos abandonados, mas ao mesmo tempo, sofremos se evitarmos este sentimento, pois não adiantaria termos o que compartilhar se não temos ninguém ao nosso lado. Portanto,

O amor perturba o indivíduo na sua totalidade, surgindo não se sabe de onde, põe o coração a pensar, a razão a sentir, torna o corpo em poesia e conduz a comportamentos e atitudes libertárias que, muitas vezes, são confundidas com a loucura ou, pelo menos, a perda de sentido da realidade das coisas. É que a linguagem do amor só é perceptível e compreensível àqueles que amam. Aos outros só resta a incompreensão ou a condenação dos que ousaram sentir, viver e falar a sua linguagem" (Marques, 2001, p. 80). 
Dessa maneira, Marques (2001) coloca que o amor pode apresentar, também, características destrutivas, ou seja, sentimentos negativos como rivalidade, medo, ciúmes e até ódio. Assim, cada relação é única, podendo iniciar por meio de uma idealização, gerando grandes expectativas, mas que no término de uma relação, pode gerar sentimentos ruins, como sofrimentos, tristezas e até mesmo ameaças, motivando uma situação perturbadora, como a própria perda de sentido da vida.

Dessa maneira, podemos pensar que o amor "no seu sentido mais amplo: é a parte essencial da vida humana, mas atua nos seus bastidores, nem por isso com pouca influência, ao contrário, com força intensa, poderosa, mas dissimulada" (Rios, 2008, p. 421).

"[...]o amor é a magia mais poderosa existente [...] tudo que é feito com amor prospera, se você não coloca o seu coração nas coisas que você realiza seja nos projetos mais básicos dos mais avançados não desenvolve. Eu até brinco "o meu coração é o meu altar" onde eu deposito a minha fé, deposito os meus objetivos, os meus projetos, está tudo ali no altar. $O$ altar é esse lugar alto, onde tudo é exposto para que seja realmente visto [...] o amor é essa energia que faz com que tudo que está em cima desse altar transcenda para um nivel mais elevado, para um nível superior [...]" (Participante 15).

Neste sentido, Moraes (2020) traz o amor para além de qualquer crença, período e contexto, se fazendo presente de maneira incrível e intensa, "na medida que não pertence a nenhuma ordem natural das coisas" (p. 164). Além disso, para o autor, o amor incondicional não pode ser exigido ou reprimido, pois ele não tem passado e nem futuro, muito menos explicações e sentidos. "O amor é cego, isto é, sem meta ou justificativa - o amor é o que é" (p. 34). Mas, se faz presente "a cada vez e a cada instante. Seu mistério é renovar-se como o mesmo, o que já sugere uma relação extraordinária com o tempo” (p. 165).

\section{$4^{\circ}$ Tema: A mudança do amor: "Enquanto a vida vai e vem. Você procura achar alguém. Que um dia possa lhe dizer. Quero ficar só com você...” (Renato Russo)}

A verdade é que amamos a vida, não porque estejamos acostumados a ela, mas porque estamos acostumados ao amor (Nietzsche)

Beraldo (2018) faz colocações sobre uma sociedade líquida, que tem seu início a a partir do final da década de 1980 e começo da década de 1990. A sociedade trazida pelo autor tem características marcadas pela velocidade, fuga e passividade das pessoas, pois estas precisam experienciar apenas coisas leves, flexíveis e rápidas, onde o consumo se faz presente em todo momento, até mesmo para se vivenciar "o amor". É neste contexto, que Bauman (2004) elabora o conceito de amor líquido, onde as relações são facilmente descartáveis, ou seja, mantidas apenas quando estiverem satisfazendo nossos desejos, mas que podem ser descartadas e encerradas facilmente.

Beraldo (2018) embasado na ideia de Bauman (2004) traz que a sociedade foi permeada por uma ideia de amor perfeito e ideal proporcionada principalmente pela mídia, por meio de filmes, séries, propagandas, livros e outros. Assim, os sujeitos acreditam que precisam desta perfeição do amor para conseguirem alcançar a felicidade plena, tanto almejada. Dessa maneira, quando os relacionamentos não atingem a perfeição, são rapidamente substituídos por outros, como mercadorias, pois a durabilidade e solidez não são priorizadas, o companheiro, ou seja, o outro, é substituído como uma mercadoria, enfatizando a desvalorização das relações, fazendo com que os sujeitos se pareçam com objetos, sem sentimento, priorizando apenas desejos.

“[...] então, para mim amor não é um sentimento é uma ação e é por isso que a gente está com uma sociedade tão doente, na minha ótica, porque as pessoas estão tentando experimentar o amor quando na verdade deveriam ofertar, ofertar para si mesmo e para o próximo. Nesse tipo, decido amar minha esposa, decido amar o meu filho e essa decisão vai provocar sim aí alguns certos sentimentos, nem sempre bons, mas amar para mim é uma decisão [...]" (Participante 6). 
Deste modo, de acordo com Bauman (2004) com a era digital, o amor se torna banalizado, prevalecendo um amor egoísta e possessivo, pois as relações precisam trazer algum tipo de retorno e evitar sofrimento, uma vez que este não é permitido na sociedade atual, por isso, precisamos manter o controle, viver somente o momento e nos preocupar prioritariamente conosco, esquecendo o outro, assim, nada precisa ser sólido e duradouro.

"[...] e o amor está tão dificill, as coisas estão muito artificiais e o amor fica muito vazio, um ideal vazio, porque a maioria das pessoas hoje não está disposta a entrega [...] entrega não é uma submissão, porque o amor não é submissão, não é aceitar as cegas também, ele é uma coisa pura, onde não tem maltrato, não tem dor, não deve haver sofrimento de maneira alguma, pelo contrário, felicidade, prazer, todo o sentimento que constrói, que fazem você se sentir bem, hoje, amanhã e por todos os dias da sua vida [...]. Então, infelizmente, hoje isso fica muito a desejar [...]” (Participante 15).

Segundo Rios (2008) na contemporaneidade, o amor fica apenas na fantasia, o que existe é retração e não entrega, pois, para ser verdadeiro de qualidade, o amor não pode ser rápido e fácil, por isso na maioria das vezes a escolha acaba sendo a solidão. Assim,

O encapsulamento é um recurso de proteção contra o incômodo, a decepção, e o custo da relação intersubjetiva, que requer o exercício da tolerância, da reflexão, do diálogo, da autocrítica e do esforço para mudar... (que, só de pensar, dá canseira, imagina pôr em prática) (p. 424).

Ainda segundo o autor acima, "amar dá trabalho. E o ganho pode parecer pouco - especialmente quando se vive em um mundo como o nosso, que nos cobra a busca por um fictício estado prazeroso ininterrupto" (p. 424).

“[...] dessa maneira amar não dá para ser simples, pois, o amor além de bonito, é complexo também, porque há diversas percepções por que o que é amor para mim, pode não ser para você e a forma como você expressa esse amor, eu percebo de uma maneira totalmente diferente e aí complica e é onde entram as desavenças, porque a forma como eu percebo esse amor não corresponda com o que eu idealizei e aí entra todos os problemas que envolvem questões do amor e como o amor é complexo existem diversas faces [...] então, perceber cada uma delas e seus aspectos, principalmente o social é delicado. É um estudo também para toda a vida, amar é uma coisa que a pessoa tem que realmente estar disposta. Amar é uma questão de disposição [...]”" (Participante 15).

Com estes contornos, o que vemos atualmente, é uma busca insana por uma felicidade perfeita e plena, que não existe, um desejo que toma conta de todos, por isso, muitos veem nos relacionamentos um meio de obter este desejo. Entretanto, assim, como todos os outros desejos, quando alcançado não mais satisfaz, pois percebemos que não é perfeito e não traz apenas sentimentos positivos. Portanto, o sujeito pós-moderno passa a ter uma vida mais solitária, pois prefere viver sozinho e livre, contudo, a pressão constante para pela perfeição, acaba fortalecendo angustias e o consumo exacerbado. Com isso, o "medo toma conta do próprio sentido da vida, demonstrando a falta de um sentido da sua própria existência" (Stein, 2016, p. 43).

A falta de relações intersubjetivas autenticas impossibilita experiências de vida que são imprescindíveis para a felicidade do eu. Ou seja, não nos bastamos, mesmo quando acreditamos que é melhor não gostar de ninguém para evitar sofrimento. Evitamos as dores de amores pelo outro e afundamos nas dores do vazio de si mesmo (Rios, 2008, p. 424).

Dessa maneira, percebemos que o amor vai corroborando com o nosso desenvolvimento, até mesmo com a formação de nosso caráter, influenciando nossas ações, atitudes e gestos, ou seja, toda a nossa vida (Maia, 2014).

\section{Considerações Finais}

Ao analisar os dados coletados por meio das entrevistas realizadas, os significados de amor, trazidos pelos diferentes atores sociais, foram diversos, no entanto, todas as falas apresentam aspectos positivos relacionados a este sentimento. Do mesmo 
modo, percebemos as mudanças e diferenças que permeiam o amor de acordo com a cultura, contexto social e a própria subjetividade de cada participante, concomitante com as transformações ocorridas com o passar do tempo, principalmente com o advento da modernidade, onde as relações do mundo contemporâneo obedecem outras lógicas, como a do consumo, por exemplo. Como graduanda em Terapia Ocupacional, ao estudar este sentimento, foi possível compreender a importância do amor em nossas vidas e no encontro com nosso sujeito-alvo. Porquanto, o processo terapêutico é permeado por uma constante transformação do próprio terapeuta e do usuário, estimulando nosso autoconhecimento e o acolhimento de si, aceitando as dificuldades, fragilidades e potências de cada um que se faz presente nos encontros de terapia ocupacional, construindo o processo ocupacional no nosso cotidiano e contexto social, de maneira significativa e subjetiva. Pois, sabemos que todas essas conquistas só são possíveis quando nos amamos e conseguimos cultivar este sentimento para conosco e nas nossas relações sociais.

Além disso, torna-se necessário que novas pesquisas específicas sejam realizadas sobre a temática, como por exemplo, trabalhos evolvendo um número maior de participantes ou o uso de escalas e avaliações padronizadas, entre outros, pois são inúmeros os aspectos envolvidos nesta temática, e, assim, a compreensão do significado de amor é muito mais ampla do que foi vista.

\section{Referências}

Aguiar, W. M. J. \& Ozella, S. (2006). Núcleos de Significação como Instrumento para a Apreensão da Constituição dos Sentidos. http://www.scielo.br/pdf/pcp/v26n2/v26n2a06.pdf>.

Almeida, T. (2017). O conceito de amor: um estudo exploratório com uma amostra brasileira. Tese de Doutorado - Programa de Pós-Graduação em Psicologia Escolar e do Desenvolvimento Humano. Universidade de São Paulo. São Paulo. https://teses.usp.br/teses/disponiveis/47/47131/tde-20092017104821/publico/Almeida_do.pdf.

Alves, A. D., Alencar, H. M. \& Ortega, A. C. (2012). Exemplos sobre a importância do amor: estudo com crianças no contexto da moralidade. Temas em Psicologia, 20(1), 261-272, 2012. http://pepsic.bvsalud.org/pdf/tp/v20n1/v20n1a19.pdf.

Aragão, J. C. S. (2011). Introdução aos estudos quantitativos utilizados em pesquisas científicas. Revista Praxis, 59. http://revistas.unifoa.edu.br/index.php/praxis/article/view/566 .

Araújo, M. F. (2002). Amor, casamento e sexualidade: velhas e novas configurações. Psicologia Ciência e Profissão, 22(2), 70-77. https://www.scielo.br/scielo.php?script=sci_arttext\&pid=S1414-98932002000200009.

Baptista, P. C. D. \& Roldão, F. D. (2017). Significados e sentidos de amor na maturidade. Anais do EVINCI - UniBrasil, 3(1), 296-296 https://portaldeperiodicos.unibrasil.com.br/index.php/anaisevinci/article/view/3379/2940.

Bastos, R. D. D. (2016). A prática do amor: a relação ética em Soren Kierkegaard. 55 P. (Trabalho de Conclusão de Curso). Universidade Federal do Maranhão. https://monografias.ufma.br/jspui/bitstream/123456789/1230/1/RaizaBastos.pdf.

Bauman, Z. (2004). Amor líquido. Jorge Zahar.

Beraldo, F. M. (2018). Amor líquido: uma reflexão sobre amar na modernidade. (Trabalho de Conclusão de Curso). Faculdade de Educação e Meio Ambiente - FAEMA. Ariquemes -RO. 65p. http://repositorio.faema.edu.br/bitstream/123456789/2328/1/TCC\%20-\%20Fabiana\%20Beraldo_Amor\%20L\%c3\%adq uido_uma\%20reflex \%c3\%a3o\%20sobre\%20am\%20ar\%20na\%20modernidade_assinado_assinado.pdf.

Braz, I. R. (2020). O amor romântico na sociedade capitalista e patriarcal: uma crítica feminista marxista. 99 P. (Mestrado). Universidade Federal de Goiás. https://repositorio.bc.ufg.br/tede/bitstream/tede/11461/3/Disserta\%C3\%A7\%C3\%A3o\%20-\%20Isana\%20Rodrigues\%20Braz\%20-\%202020.pdf.

Bystronski, B. (1995). Teorias e Processos Psicossociais da Intimidade Interpessoal. Em: Rodrigues, Aroldo. Psicologia Social para principiantes: estudo da interação humana. Petrópolis: Vozes.

Casey, J. (1992). A história da família. Editora: Ática. http://edufrn.ufrn.br/bitstream/123456789/130/157/O\%20SIGNIFICADO\%20DA\%20FAM\% C3\%8DLIA.\%20A\% 20hist\%C3\%B3ria\%20da\%20fam\%C3\%ADlia.\%20CASY\%2C\%20James.\%201992..pdf.

Cerqueira, I. C. \& Rocha, F. N. (2018). Amor e relacionamentos amorosos no olhar da psicologia. Revista Mosaico, 09(2),10-17. file:///C:/Users/Suporte\%20Notebooks/Downloads/1449-Texto\%20do\%20artigo-5170-2-10-20181206.pdf.

Chapman, G. (1997). As cinco linguagens do amor. Tradução: Iara Vasconcelos. Editora: Mundo Cristão, 1997. https://docero.com.br/doc/8nxxv15.

Domingues, S. C. (2013). O amor na sociedade. Quando a virtude se torna dor. (Trabalho de Conclusão de Curso). Universidade de Brasília. 53 p. https://1library.co/document/q208x8pz-o-amor-na-sociedade-quando-a-virtude-se-torna-dor.html. 
Gouveia, V. V., Carvalho, E. A. B., Santos, F. A. \& Almeida, M. R. (2013). Escala tetrangular do amor: Testando sua estrutura e invariância fatorial. Psicologia: Ciência e Profissão, 33(1), 32-45. https://www.scielo.br/scielo.php?script=sci_arttext\&pid=S1414-98932013000100004.

Gouveia, V. V., Fonseca, P. N., Cavalcanti, J. P. N., Diniz, P. K. C. \& Dória, L. C. (2009). Versão abreviada da Escala Triangular do Amor: Evidências de validade fatorial econsistência interna. Estudos de Psicologia, 14(1), 31-39. https://www.scielo.br/pdf/epsic/v14n1/a05v14n1.pdf.

Guedes, C. (2005). Sociabilidade e Sociedade de Risco: um estudo sobre relações na modernidade. PHYSIS: Revista de Saúde Coletiva, Rio de Janeiro, 15 (2): 353-371. https://www.scielo.br/pdf/physis/v15n2/v15n2a09.pdf.

Hernandez, J. A., Plácido, M. G., Araújo, A. L., Neves, V. C. \& Azevedo, C. A. C. B. (2014). A psicologia do amor: vinte anos de estudos científicos nacionais. Psicol. Argum., 32 (79), 131-139, 2014. file:///C:/Users/Raphaela/Downloads/20553-35539-1-SM\%20(1).pdf.

Hernandez, J. A. E. \& Oliveira, I. M. B. (2003). Os Componentes do Amor e a Satisfação. Psicologia Ciência e Profissão. 21(3), 58-69. https://www.scielo.br/pdf/pcp/v23n1/v23n1a09.pdf.

Johnson, R. A. (1987). A Chave do Entendimento da Psicologia Feminina, SP, Ed. Mercuryo. https://www.docsity.com/pt/johnson-r-a-we-a-chave-dapsicologia-do-amor-romantico/4834263/.

Lins, N. R. (2012). O livro do amor. Volume I: Da Pré-História à Renascença. Editora: BestSeller.

Marques, R. (2001). O livro das virtudes de sempre: ética para professores. Landy.

Martuccelli, D. (2016). O indivíduo, o amor e $\quad$ o $\quad$ sentido da vida. Estudos Avançados, 30 (86). https://www.scielo.br/j/ea/a/VvXTsfZHkNKBkSpKCn8gMzt/?lang=pt\&format=pdf.

Maia, R. A. S. (2014). O significado do Amor: uma comparação contemporânea e teológica de sua ocorrência e significados. Revista de Cultura Teológica. $\mathrm{n}^{\circ}$ 83. file:///C:/Users/Suporte\%20Notebooks/Downloads/19235-51732-1-PB.pdf.

Michelis, (2021). DICIONÁRIO MICHAELIS. Editora Melhoramentos. https://michaelis.uol.com.br/moderno-portugues/busca/portugues-brasileiro/amor/.

Minayo, M. C. S., Deslandes, S.F. \& Gomes, R. (2001). Pesquisa social: teoria, método e criatividade. (18a ed.), Editora Vozes.

Moraes, D. (2020). O acontecimento do amor: ensaio para a recolocação da essência do amor humano [recurso eletrônico]/ Dax Moraes. Ed. Da UFCSPA, 2020. file:///C:/Users/Raphaela/Downloads/O-acontecimento-do-amor\%20(1).pdf.

Gimenez, R. M. \& Bervique, J. A. (2006). Relação entre as emoções e o organismo como um todo. Revista Científica Eletrônica de Psicologia, ano IV, n. 7, novembro. http://faef.revista.inf.br/imagens_arquivos/arquivos_destaque/ri4hKpL8RT19wi8_2013-5-10-15-32-13.pdf.

Nascimento, D. F. M. P. (2019). História Filosófica do Amor: Ensaio para uma nova compreensão da essência do amor humano. EDUFRN. https://repositorio.ufrn.br/jspui/bitstream/123456789/27912/1/Hist\%C3\%B3ria\%20Filos\%C3\%B3fica\%20do\%20Amor.pdf.

Preto, Z., Maheirie, K. \& Tonelli, M. J. F. (2009). Um olhar sobre o amor no ocidente. Psicologia em Estudo, 14(2), 395-403, https://www.scielo.br/j/pe/a/BrwsMQ66MGnKHskw6qcQ3Bf/?lang=pt\&format=pdf.

Quadros, E. M. (2011). Eros, Fília e Ágape: o amor do mundo grego à concepção cristã. Acta Scientiarum. Human and Social Sciences, 33(2), 165-171. file://C:/Users/Raphaela/Downloads/10173-Texto\%20do\%20artigo-61595-1-10-20111219\%20(1).pdf.

Reichow, L. D. K. Individualismo, hedonismo e narcisismo na hipermodernidade. (2015). Anais do Salão de Pesquisa da Faculdade EST. EST, 14. file:///C:/Users/Suporte\%20Notebooks/Downloads/624-2029-1-PB.pdf.

Rios, I. C. (2008). O amor nos tempos de Narciso. Interface. Comunicação Saúde Educação, 12(25), 421-426, https://www.scielo.br/j/icse/a/kYk5fRB4XmhKkHXLjSsj46w/?format=pdf\&lang=pt.

Scholosser, A. (2014). Interface entre Saúde Mental e Relacionamento Amoroso: Um Olhar a Partir da Psicologia Positiva. Pensando Famílias, 18(2), 17-33. http://pepsic.bvsalud.org/pdf/penf/v18n2/v18n2a03.pdf.

Silva, P. O. M., Trindade, Z. A. \& Júnior, A. S. (2013). Teorias Sobre o Amor no Campo da Psicologia Social. Psicologia: Ciência e Profissão, 33(1), 16-31. https://www.redalyc.org/pdf/2820/282026452004.pdf.

Silva, M. A. D. S. (2014). Quem ama não adoece. Editora: BesSeller.

Silva, L. C. (2002). Emoções e sentimentos na escola: uma certa dimensão do domínio afetivo. 374 P. (MESTRADO). Universidade Federal da Bahia. https://repositorio.ufba.br/ri/bitstream/ri/11773/1/Silva\%2C\%20Lindomar.pdf

Stein, D. J. Amor líquido e as relações pessoais frágeis: uma proposta de leitura da representação da mulher canalha em contos de canalha: substantivo feminino e na série televisiva as canalhas. (2016).108 P. (Mestrado). Universidade Regional Integrada do Alto Uruguai e das Missões. http://www.fw.uri.br/NewArquivos/pos/dissertacao/dis-132.pdf.

Vasconcelos, T. S. F. (2013). A influência das relações de apego entre pais e filhos na compreensão das emoções pelos filhos. Dissertação de Mestrado da

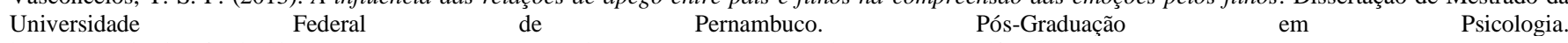
https://repositorio.ufpe.br/bitstream/123456789/10444/1/Disserta\%C3\%A7ao\%20Tha\%C3\%AFs.pdf. 